\title{
PENDEKATAN ETNOSAINS DALAM PELAJARAN KIMIA UNTUK PEMBENTUKAN KARAKTER SISWA: TANGGAPAN GURU KIMIA DI NTB
}

\section{ETHNOSAINS APPROACH IN CHEMISTRY LEARNING FOR THE ESTABLISHMENT OF STUDENT CHARACTER: CHEMISTRY TEACHER RESPONSE IN NTB}

\author{
Yayuk Andayani $^{1 *}$, Yunita Arian Sani Anwar ${ }^{2}$, dan Saprizal Hadisaputra ${ }^{2}$ \\ ${ }^{1}$ Program Studi Pendidikan IPA, Pascasarjana Universitas Mataram, Mataram, Indonesia \\ ${ }^{12}$ Program Studi Pendidikan Kimia FKIP Universitas Mataram, Indonesia \\ *Email: yayukmtr@gmail.com
}

Diterima: 10 Desember 2020. Disetujui: 2 Januari 2021. Dipublikasikan: 9 Januari 2021

\begin{abstract}
Abstrak: Pembelajaran saat ini mengutamakan terwujudnya karakter yang baik pada peserta didik. Penggunaan etnosains sebagai pendekatan diharapkan mampu mewujudkan hal tersebut. Namun, hingga saat ini pendekatan etnosains belum banyak dilakukan dalam pembelajaran kimia. Sebagai upaya mengembangkan model pembelajaran kimia berbasis etnosains perlu dilakukan penelitian terkait tanggapan guru kimia selaku praktisi terhadap pendekatan etnosains dalam pembentukan karakter siswa melalui pembelajaran kimia. Penelitian ini merupakan penelitian kualitatif dengan melibatkan 113 guru kimia sebagai responden. Alat pengumpul data yang digunakan adalah kuesioner yang berisi pernyataa terkait pembelajaran kimia dan pendekatan etnosains. Hasil penelitian menemukan bahwa sebagian besar guru belum menggunakan pendekatan etnosains dalam pelaksanaan pembelajaran kimia baik pembelajaran di kelas maupun di laboratorium. Pembelajaran kimia dengan pendekatan etnosains perlu dikembangkan untuk dapat membangun karakter siswa. Perlu dikembangkan model pembelajaran dan modul pembelajaran dengan memasukkan unsur budaya dan sesuai dengan kurikulum 2013 agar siswa lebih memahami konsep kimia dan mengenal budaya sekitar sehingga mengubah persepsi siswa bahwa kimia dekat dengan kehidupan sehari-hari.
\end{abstract}

Kata Kunci: Etnosains, pembelajaran kimia, karakter siswa

\begin{abstract}
Current learning prioritizes the creation of good character in students. The use of ethnoscience as an approach is expected to be able to make this happen. However, until now the ethnoscience approach has not been widely used in chemistry studies. In an effort to develop a chemistry learning model based on ethnoscience, it is necessary to conduct research related to the responses of chemistry teachers as practitioners to the ethnoscience approach in building student character through chemistry learning. This study is a qualitative study involving 113 chemistry teachers as respondents. The data collection tool used was a questionnaire containing statements related to chemistry learning and the ethnoscience approach. The results of the study found that most of the teachers had not used the ethnoscience approach in the implementation of chemistry learning, both in class and in the laboratory. Chemistry learning with an ethnoscience approach needs to be developed to be able to build student character. It is necessary to develop a learning model and learning module by incorporating cultural elements and in accordance with the 2013 curriculum so that students better understand the concept of chemistry and get to know the surrounding culture so as to change students' perceptions that chemistry is close to everyday life.
\end{abstract}

Keywords: Ethnosaince, chemistry learning, student character

\section{PENDAHULUAN}

Pengembangan karakter merupakan hal fundamental yang perlu dilakukan dalam bidang pendidikan. Karakter mencakup semua pikiran, perasaan, kata-kata, serta tindakan yang dapat mempengaruhi masa depan siswa [1]. Hal inilah yang menjadi perhatian penting pemerintah dalam penerapan kurikulum 2013. Perubahan dalam proses pembelajaran lebih ditekankan pada pembelajaran kontekstual dan menyenangkan bagi siswa. Selain itu, penerapan aspek budaya penting diintegrasikan dalam proses pembelajaran untuk mempertahankan identitas bangsa Indonesia dan membentuk karakter siswa.

Penerapan kurikulum 2013 tentunya menyebabkan perubahan pada kurikulum kimia. Jika sebelumnya kimia menjadi mata pelajaran utama, maka saat ini kimia menjadi mata pelajaran peminatan yang dapat memberikan kesempatan pada siswa dalam mengembangkan minatnya sesuai keinginan mereka dalam memilih jurusan kimia di Perguruan Tinggi. Hal ini menuntut kreatifitas guru dalam melaksanakan pembelajaran sehingga siswa tidak hanya senang belajar kimia, namun juga siswa merasa bahwa kimia bermanfaat bagi mereka dan dapat menumbuhkan kebiasaan yang baik yang berguna bagi masa depan mereka.

Karakter dapat dibangun dengan beberapa strategi di antaranya berperan sebagai model dan mentor; membentuk komunitas yang bermoral; menerapkan disiplin moral; menciptakan lingkungan sekolah yang demokrasi; mengajar karakter melalui kurikulum seperti menggunakan bacaan, budaya, dan 
sains; menggunakan pembelajaran kooperatif; dan mengembangkan "conscience of craft" [2]. Pada tatanan pendidikan, karakter siswa dapat dikembangkan melalui kurikulum di sekolah dengan menggunakan indikator karakter berdasarkan pembelajaran abad 21 yaitu rasa ingin tahu, keterbukaan, kepemimpinan, dan etika [3-5]. Namun, belum banyak yang melibatkan pendidikan karakter dalam kurikulum [6].

Budaya merupakan hal komplek yang terdiri atas pengetahuan, kepercayaan, seni, moral, hukum, dan segala hal yang menjadi kebiasaan masyarakat. Karakteristik budaya yang mencakup nilai, sikap dan pengetahuan dapat menjadi unsur penting dalam pengembangan karakter siswa. Hal inilah yang melatarbelakangi pengembangan pendekatan etnosains dalam proses pembelajaran [7].

Etnosains merupakan suatu pendekatan yang menghubungkan aplikasi sains dalam kehidupan masyarakat sehingga sains dan budaya menjadi terhubung dalam pembentukan karakter siswa [8]. Pendekatan ini dimaksudkan untuk mendekatkan siswa dengan lingkungan sekitarnya. Beberapa laporan penelitian melaporkan bahwa praktik dan persepsi lokal dapat melatih keterampilan berpikir dan proses siswa [9].

Rist \& Dahdouh-Guebas [9] menguraikan manfaat pendekatan etnosains dalam proses pembelajaran. Selain menciptakan kesadaran untuk menggali budaya melalui pemangku kepentingan dan komunitas sosial lainnya, etnosains dapat berkontribusi dalam menyiapkan wadah untuk membantu penyelesaian masalah sosial dan berperan aktif dalam proses sosial sehingga membantu pemangku kepentingan dalam merumuskan kebijakan dan implementasinya.

Penggunaan pendekatan etnosains dalam pembelajaran kimia hingga kini belum banyak yang melaporkan. Agar memudahkan proses pengembangannya dalam kegiatan pembelajaran, perlu kiranya menghimpun respon dari guru-guru kimia selaku praktisi dalam proses pembelajaran kimia. Penelitian ini bertujuan untuk mengeksplor pendapat dan saran guru terkait dengan pendekatan etnosains dalam pembelajaran kimia.

\section{METODE PENELITIAN}

Penelitian ini termasuk penelitian kualitatif untuk mengkaji pendekatan etnosains dalam pembelajaran kimia. Teknik yang digunakan adalah kuesioner untuk membantu peneliti dalam memperoleh informasi terkait pendekatan etnosains dalam pembelajaran kimia di NTB. Menurut Wellington [10] kuesioner merupakan instrumen yang efektif untuk mengkoleksi data pada penelitian kualitatif.

\section{Partisipan}

Partisipan pada penelitian ini adalah guru-guru kimia pada sekolah menengah di Nusa Tenggara Barat. Jumlah sampel sebanyak 113 guru dengan faktor demografi seperti yang ditunjukkan pada Tabel 1.
Tabel 1. Ringkasan Demografi Sampel

\begin{tabular}{lcc}
\hline \multicolumn{1}{c}{ Identitas } & Jumlah & $\%$ \\
\hline $\begin{array}{l}\text { Jenis Sekolah } \\
\text { Negeri }\end{array}$ & 94 & 83.18 \\
Swasta & 19 & 16.82 \\
\hline Usia Guru (tahun) & & \\
$>45$ & 16 & 14.16 \\
$<45$ & 97 & 85.84 \\
\hline Jenis Kelamin & & \\
Laki-Laki & 28 & 24.78 \\
Perempuan & 85 & 75.22 \\
\hline Status Kepegawaian & & \\
Guru Honorer & 34 & 30.09 \\
PNS & 79 & 69.91 \\
\hline Pengalaman Mengajar & & \\
$>10$ & 77 & 68.14 \\
$<10$ & 36 & 31.86 \\
\hline Kualifikasi Akademik & & \\
Kimia & 14 & 12.4 \\
Pendidikan Kimia & 83 & 73.45 \\
Pendidikan IPA & 13 & 11.5 \\
Lain-lain & 3 & 2.65 \\
\hline Sertifikasi Guru & & \\
Sudah Tersertifikasi & 72 & 63.72 \\
Belum Tersertifikasi & 41 & 36.28 \\
\hline
\end{tabular}

\section{Instrumen}

Instrumen yang digunakan adalah kuesioner dengan tiga indikator. Indikator kuesioner meliputi:

1. Persiapan pelaksanaan pembelajaran sesuai K-13

2. Pemahaman tentang pendekatan etnosains

3. Tanggapan tentang pengembangan pembelajaran kimia dengan pendekatan etnosains.

Masing-masing indikator dikembangkan menjadi beberapa pernyataan dengan dengan pilihan jawaban yang sesuai. Instrumen yang telah disusun dianalisis oleh 3 orang ahli menggunakan indeks kesepakatan Aiken untuk mengetahui instrumen layak digunakan sebagai alat ukur. Instrumen yang dinyatakan layak disusun dalam bentuk google form dan dikirim ke guru-guru kimia di Nusa Tenggara Barat.

\section{Analisis Data}

Rata-rata setiap pernyataan pada masingmasing indikator ditabulasi dan dihitung persentasenya. Dilakukan analisis terkait dengan kecenderungan tanggapan guru berdasarkan variasi sampel. Free respon data yang diberikan oleh masing-masing responden dikelompokkan dalam beberapa kategori dan dideskripsikan.

\section{HASIL DAN PEMBAHASAN}

Analisis kuesioner pada indikator persiapan pembelajaran sesuai K-13 menunjukkan persentase yang bervariasi pada seluruh pernyataan. Sebanyak $79.65 \%$ guru telah menyusun silabus kimia sesuai dengan kurikulum 2013; 63.03\% guru telah memperdalam kompetensi dasar dan standar isi sesuai dengan kebutuhan siswa pada pembelajaran kimia; 
sebanyak $61.95 \%$ guru kimia telah memperdalam kompetensi dasar dan standar isi sesuai dengan karakteristik siswa pada pembelajaran kimia; $76.99 \%$ guru telah mengembangkan sejumlah indikator dalam silabus yang mencerminkan pencapaian kompetensi pada pembelajaran kimia; sebanyak $85.84 \%$ guru telah menyusun RPP setiap pelaksanaan pembelajaran kimia; sebanyak $87.61 \%$ dalam RPP yang disusun guru, tujuan pembelajaran mencerminkan pencapaian indikator dan kompetensi dasar; dan sebanyak $79.65 \%$ guru mengorganisasikan materi pembelajaran kimia secara urut untuk pencapaian kompetensi.

Responden yang belum pernah menyusun silabus kimia sesuai dengan kurikulum 2013 sebanyak $20.35 \%$ didominasi oleh responden yang kualifikasi akademik dengan usia dibawah 45 tahun dan mengajar di sekolah swasta. Hal yang sama ditunjukkan pada pernyataan mengembangkan sejumlah indikator dalam silabus yang mencerminkan pencapaian kompetensi pada pembelajaran kimia; menyusun RPP setiap pelaksanaan pembelajaran kimia; RPP yang disusun guru, tujuan pembelajaran mencerminkan pencapaian indikator dan kompetensi dasar; dan guru mengorganisasikan materi pembelajaran kimia secara urut untuk pencapaian kompetensi. Pada indikator memperdalam kompetensi dasar dan standar isi sesuai dengan kebutuhan siswa dan karakteristik siswa pada pembelajaran kimia tidak hanya didominasi oleh hal yang disebutkan di atas namun juga diwakili oleh guru yang bertugas di sekolah negeri dengan usia di atas 45 tahun.

Tanggapan terkait pendekatan etnosains sebanyak $9.74 \%$ responden mengetahui maksud dari pendekatan etnosains dan didominasi oleh responden dengan usia di bawah 45 tahun dengan masa kerja di bawah 10 tahun. Untuk responden dengan usia di atas 45 tahun dan masa kerja di atas 10 tahun mereka lebih banyak belum mengetahui pendekatan etnosains. Hal yang sama juga terlihat pada pernyataan mengikutsertakan budaya sekitar (benda bersejarah atau kebiasaan masyarakat) dalam proses pembelajaran kimia, sebanyak $90.26 \%$ responden belum pernah melakukannya dengan tanggapan yang diberikan oleh hampir semua kriteria responden. Pernyataan melaksanakan pembelajaran kimia yang membangun karakter siswa sebanyak $35.4 \%$ responden telah melaksanakannya dan kriteria responden cenderung acak, namun sebanyak $64.6 \%$ lebih banyak tidak memahami pembelajaran yang membangun karakter dan melaksanakan proses pembelajaran lebih pada pendalaman konsep saja. Pernyataan terkait dengan modul kimia yang mengandung unsur budaya semua responden memberi tanggapan belum pernah membaca dan menemukan modul seperti itu. Secara umum terkait pendekatan etnosains pada pembelajaran kimia ditunjukkan pada Gambar 1.

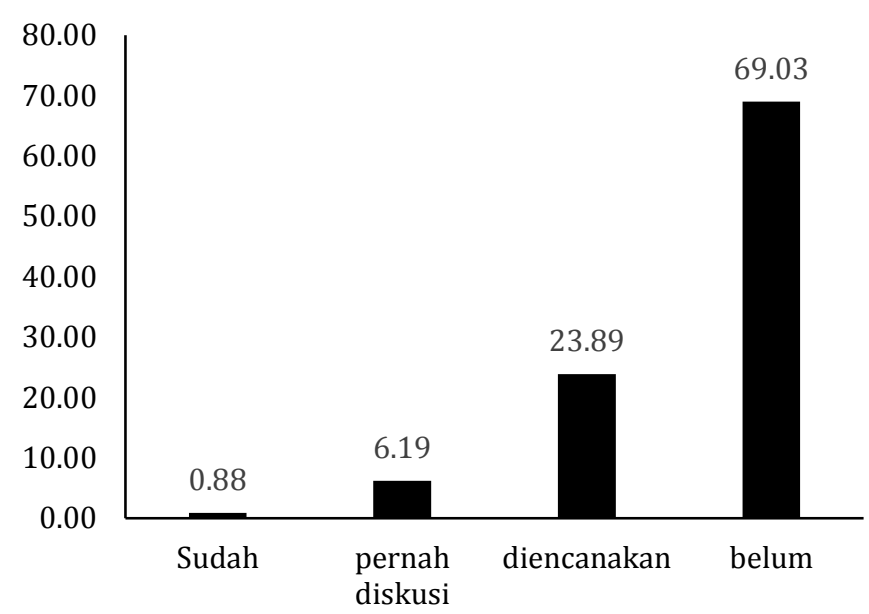

Gambar 1. Respon terhadap pendekatan etnosains

Pelaksanaan praktikum merupakan proses pembelajaran yang tidak dapat dipisahkan dengan pembelajaran kimia. Sebanyak $69.03 \%$ responden telah melaksanakan praktikum kimia sebagai bagian dari proses pembelajaran. Namun, sebanyak $30.97 \%$ responden belum pernah melaksanakan praktikum karena keterbatasan alat dan bahan di lokasi mengajar. Respon ini lebih banyak diberikan oleh guru yang bertugas di sekolah swasta. Sebanyak $9.74 \%$ responden melaksanakan praktikum dengan memanfaatkan lingkungan sekitar sedangkan responden lainnya menyatakan bahwa pelaksanaan praktikum dengan menggunakan bahan yang tersedia di laboratorium. Respon yang sama juga ditunjukkan oleh responden pada pernyataan menggunakan sains sederhana yang ada di masyarakat pada pembelajaran kimia di kelas dan menggunakan sains sederhana yang ada di masyarakat pada praktikum kimia.

Respon secara terbuka pada responden menunjukkan bahwa sebanyak 74.34\% guru berpendapat sangat perlu dikembangkannya model pembelajaran kimia yang dapat membangun karakter siswa dan sebanyak $53.98 \%$ perlu mengikutsertakan budaya dalam pembelajaran kimia. Beberapa alasan menarik yang diungkapkan oleh responden bahwa pendekatan etnosains diharapkan dapat memudahkan siswa untuk memahami konsep kimia dan mengenal budaya di sekitarnya. Berikut ini adalah beberapa tanggapan responden:

"Pembelajaran kimia menggunakan pendekatan budaya sepertinya akan lebih memudahkan siswa untuk memahami konsep atau materi kimia karena berhubungan dengan lingkungan atau kehidupan mereka”

"Pembelajaran kimia menggunakan pendekatan budaya perlu dikembangkan untuk meningkatkan kecintaan siswa pada budaya lokal. Selain itu juga untuk meningkatkan pembelajaran konseptual, bahwa kimia juga ada dalam kehidupan sehari-hari", 
"Pendekatan budaya dalam pembelajaran kimia sangat bagus untuk digunakan sehingga peserta didik lbh tertarik dan mengetahui peranan kimia dalam kehidupan dan mohon

Penggunaan etnosains sebenarnya dapat menjadi tingkatan makroskopik yang penting dalam membuat pembelajaran lebih menarik. Salah satu masalah pembelajaran kimia dan sains yang sering dilaporkan adalah pembelajaran yang belum menghubungkan tingkatan makroskopik dan mikroskopik dengan baik [11-14]. Aspek sosial juga menjadi penting dalam proses pembelajaran dimana saat ini aspek kognitif masih mendominasi [15-17].

Penggunaan etnosains dapat juga berperan dalam proses pembentukan karakter siswa [18]. Jika proses pembelajaran dapat mengintegrasikan aspek kognitif, sikap dan keterampilan maka pembelajaran dapat dikatakan bermakna untuk dilakukan [19-21]. Harapan ini yang diharapkan apabila pendekatan etnosains dapat digunakan dalam proses pembelajaran kimia.

\section{KESIMPULAN}

Pembelajaran kimia dengan pendekatan etnosains perlu dikembangkan untuk dapat membangun karakter siswa. Perlu dikembangkan model pembelajaran dan modul pembelajaran dengan memasukkan unsur budaya dan sesuai dengan kurikulum 2013 agar siswa lebih memahami konsep kimia dan mengenal budaya sekitar sehingga mengubah persepsi siswa bahwa kimia dekat dengan kehidupan sehari-hari.

\section{UCAPAN TERIMA KASIH}

Penelitian ini dibiayai oleh dana PNBP Pascasarjana Universitas Mataram Tahun 2020.

\section{DAFTAR PUSTAKA}

[1] McElmeel, S.L. (2002). Character education: a book guide of teachers, librarians, and parents. Greenwood Village, Co: Teacher Ideas Press.

[2] Pala, A. (2011). The need for character education. International Journal of Social Sciences and Humanity Studies, 3(2), 23-32.

[3] Agboola, A., \& Tsai, K.C. (2012). Bring character education into classroom. European Journal of Educational Research, 1(2), 163-170.

[4] Bialik, M., Bogan, M., Fadel, C., \& Horvathova, M. (2015). Character education for the 21 st century: what should students learn. Center for Curriculum Redesign: Massachusetts.

[5] Bajovic, M., Rizzo, K., \& Engmann, J. (2009). Character education re-conceptualized for practical implementation. Canadian Journal of Educational Administration and Policy, 92, 1-23.

[6] Ghamrawi, N.A.R., Ghamrawi, N., \& Shal, T. (2015). Perception of character education: the case of Lebanese school leaders. Open Journal of Leadership, 4, 129-142. kepada bpk/dosen untuk bisa membimbing para guru agar bisa memberikan konsep kimia yang terhubung dengan kebudayaan masyarakat setempat"

[7] Ibe, E., \& Nwosu, A.A. (2017). Effects of Ethnoscience and traditional laboratory practical on science process skills acquisition of secondary school biology students in Nigeria. British Journal of Multidisciplinary and Advanced Studies, 1(1), 35-46.

[8] Utari, R., Andayani, Y., \& Savalas, L. R. T. (2020). Pengembangan Modul Kimia Berbasis Etnosains Dengan Mengangkat Kebiasaan Petani Garam. Jurnal Pijar Mipa, 15(5), 477-480.

[9] Rist, S., \& Dahdouh-Guebas, F. (2006). Ethosciences-a step towards the integration of scientific and indigenous forms of knowledge in the management of natural resources for the future. Environ Dev Sustain, 8, 467-493.

[10] Wellington, J.J. (1996). Methods and Issues in Educational Reaserch. London: Impact Graphics.

[11]Broman, K., Ekborg, M., \& Johnels, J. Chemistry in crisis? Perspectives on teaching and learning chemistry in Swedish upper secondary schools. Nordina Vol 7(No.1). (2011) 43-53.

[12] Conway, J.C. (Effects of guided inquiry versus lecture instruction on final grade distribution in a one-semester organic and biochemistry course. Journal of Chemical Education Vol. 91(No.4) (2014) 480-483. doi: 10.1021/ed300137z

[13] Cheung, D. Evaluating student attitudes toward chemistry lessons to enhance teaching in the secondary schools. Educación Química Vol. 22(No.2) (2011)1-8.

[14] Anderson, T.R., \& Grayson, D.J. (1994). Improving students' understanding of carbohydrate metabolism in first-year biochemistry at tertiary level. Research in Science Education, 24, 1-10.

[15] Erduran, S. (2013). Philosophy, chemistry, and education: an introduction. Science and Education, 22, 1559-1562. doi: 10.1007/s1119-012-9526-9.

[16] Holbrook, J. (2005). Making chemistry teaching relevant. Chemical Education International, 6(1), $1-12$.

[17] Johnstone, A.H. Chemical education research in glasgow in perspective. Chemistry Education Research and Practice Vol. 7(No.2) (2006) 49-63.

[18] Agboola, A., \& Tsai, K.C. (2012). Bring character education into classroom. European Journal of Educational Research, 1(2), 163-170.

[19] Galloway, K.R., \& Bretz, S.L. Measuring meaningful learning in the undergraduate general chemistry and organic chemistry laboratories: a longitudinal study. Journal of Chemical Education Vol. 92(No.12) (2015) 2019-2030.

[20] Bretz, S.L., Fay, M., Bruck, L.B., \& Towns, M.H. What faculty interviews reveal about meaningful learning in the undergraduate chemistry laboratory. 
J. Pijar MIPA, Vol. 16 No.1, Januari 2021: 39-43

ISSN 1907-1744 (Cetak)

DOI: $10.29303 /$ jpm.v16i1.2269

ISSN 2460-1500 (Online)

Journal of Chemical Education Vol. 90 (2013) 281288.

[21] Vallori, A.B. Meaningful learning in practice. Journal of Education and Human Development Vol. 3 (No.4) (2014) 199-209. 